\title{
The apotheosis of conservation agriculture- A review
}

\author{
M. M. Hossain* \\ Department of Agronomy, Bangladesh Agricultural University, Mymensingh-2200, Bangladesh, *E-mail: \\ mmhshakil@yahoo.com
}

\begin{abstract}
This paper focuses on conservation agriculture (CA), defined as minimal soil disturbance (no-till) and crop residue retention (mulch) combined with crop rotations. The paper then describes the principles based on which CA runs with briefing suggested improvement on conservation tillage, where no-till, mulch and rotations significantly improve soil properties and other biotic factors. This paper also describes some cons of CA with its future strategies. A Case study from the rice-wheat areas of the Indo-Gangetic Plains of South Asia used to describe how CA practices have been used to raise production sustainably and profitably. Benefits in terms of greenhouse gas emissions and their effect on global warming are also discussed. The paper concludes that agriculture in the next decade will have to sustainably produce more food from less land through more efficient use of natural resources and with minimal impact on the environment in order to meet growing population demands. Promoting and adopting CA management systems can help meet this goal.
\end{abstract}

Keywords: Conservation agriculture, Direct seeding, Zero-tillage, Mulching, Crop rotation Rice-wheat system

\section{Introduction}

Conservation agriculture (CA) is a model of sustainable agriculture as it leads to profitable crops production while protecting and even restoring natural resources. CA benefits farmers because it reduces production costs and increases yields through the betterment soil fertility, improvement of water quality, reduction of erosion and mitigation of climate change by increasing carbon sequestration, etc. CA systems are also less sensitive to extreme climatic events and therefore contribute to the adaptation to climate change and the resilience of agricultural systems. Hence, CA becomes a fundamental element of sustainable production intensification, combining high production with the provision of environmental services.

CA is gaining acceptance in many parts of the world as an alternative to both conventional agriculture and to organic agriculture. Although the practice of CA on a large scale emerged out of Brazil and Argentina, similar developments were occurring in many other areas of the world, notably North America in zero tillage, and Africa and Asia with technologies such as agroforestry (Dumanski et al., 2006). CA is based on the principles of rebuilding the soil optimizing crop production inputs, including labour and optimizing profits. Applied together, CA practices - no tillage, permanent soil cover, use of cover crops and crop rotations have complementary positive outcomes: no tillage maintains stable soil structure and biological activity; a permanent organic soil cover protects the soil surface from erosion and creates a stable and favorable micro-climate; cover crops provide organic matter, reduce erosion and improve soil fertility; and crop rotation enhances the biodiversity of the system and therefore contributes to weed, pest and disease control (Berger et al., 2010).

In South Asia (India, Pakistan, Nepal and Bangladesh) there is a significant interest in CA. No-till wheat is grown on more than 4 million ha. The adoption of full CA, i.e., permanent no-till for all rotational crops, remains marginal. The Indian Professional Alliance for Conservation Agriculture is promoting and developing CA practices. The expansion is likely to be fast and widespread as there is a general interest in resource saving technologies in these regions.

CA aims to achieve sustainable and profitable agriculture and subsequently aims at improved livelihoods of farmers through the application of the three CA principles: minimal soil disturbance, permanent soil cover and crop rotations. CA holds tremendous potential for all sizes of farms and agro-ecological systems, but its adoption is perhaps most urgently required by smallholder farmers, especially those facing acute labour shortages. It is a way to combine profitable agricultural production with environmental concerns and sustainability and it has been proven to work in a variety of agro-ecological zones and farming systems. It is been perceived by practitioners as a valid tool for sustainable land management (FAO, 2007). 


\section{Definition of Conservation Agriculture}

Agriculture is one of the most important sectors in the economies of most nations (New Standard Encyclopedia, 1992). At the same time conservation is the use of resources in a manner that safely maintains a resource that can be used by humans. Conservation has become critical on the fact that the world population has increased over the years and more food needs to be produced every year (New Standard Encyclopedia, 1992). Sometimes referred to as "agricultural environmental management", conservation agriculture may be sanctioned and funded through conservation programs promulgated through agricultural legislation.

CA can be defined by a statement given by the Food and Agriculture Organization of the United Nations as "a concept for resource-saving agricultural crop production that strives to achieve acceptable profits together with high and sustained production levels while concurrently conserving the environment" (FAO, 2007).

CA is the integration of ecological management with modern, scientific and agricultural production. CA employs all modern technologies that enhance the quality and ecological integrity of the soil, but the application of these is tempered with traditional knowledge of soil husbandry gained from generations of successful farmers. This holistic embrace of knowledge, as well as the capacity of farmers to apply this knowledge and innovate and adjust to evolving conditions, ensures the sustainability of those who practice CA. A major strength of CA is the step-like implementation by farmers of complementary, synergetic soil husbandry practices that build to a robust, cheaper, more productive and environmentally friendly farming systems. These systems are more sustainable than conventional agriculture because of the focus of producing with healthy soils.

$\mathrm{CA}$ is based on enhancing natural biological production levels while processes above and below the ground. Interventions such as mechanical soil tillage are reduced to an absolute minimum, and the use of external inputs such as agrochemicals and nutrients of mineral or organic origin are applied at an optimum level and in a way and quantity that does not interfere with, or disrupt, the biological processes. CA is characterized by three principles which are linked to each other, namely: (1) continuous minimum mechanical soil disturbance; (2) permanent organic soil cover; and (3) diversified crop rotations in the case of annual crops or plant associations in case of perennial crops.

In conservation agriculture there are many examples that can be looked towards as a way of farming but at the same time conserving. These practices that are done now are known well by most producers. The process of no-till is one that follows the first principle of CA, with doing minimal mechanical soil disturbance. No-till also brings other benefits to the producer. According to the FAO tillage is one of the most "energy consuming" processes that can be done: It takes a lot of labor, time, and fuel to till. Producers can save $30 \%$ to $40 \%$ of time and labor by practicing the no-till process (FAO, 2006).

Besides conserving the soil, there are other examples of how CA is used. According to an article in Science called "Farming and the Fate of Wild Nature" there are two more kinds of CA. The practice of wildlife-friendly farming and land sparing are ideas for producers who are looking to be more conservative towards biodiversity (Green et al., 2005).

\section{Principles of Conservation Agriculture}

The Food and Agricultural Organization of the United Nations (FAO) has determined that CA has three key principles that producers (farmers) can proceed through in the process of CA. These three principles outline what conservationists and producers believe can be done to conserve what we use for a longer period of time.

The first key principle in CA is practicing minimum mechanical soil disturbance which is essential to maintaining minerals within the soil, stopping erosion, and preventing water loss from occurring within the soil. In the past agriculture has looked at soil tillage as a main process in the introduction of new crops to an area. It was believed that tilling the soil would increase fertility within the soil through mineralization that takes place in the soil. Also tilling of soil can cause severe erosion and crusting which will lead to a 
decrease in soil fertility. Today tillage is seen as a way of destroying organic matter that can be provided within the soil cover. No-till farming has caught on as a process that can save soils organic levels for a longer period and still allow the soil to be productive for longer periods (FAO, 2007).

When no-till practices are followed, the producer sees a reduction in production cost for a certain crop. Tillage of the ground requires more money due to fuel for tractors or feed for the animals pulling the plough. The producer sees a reduction in labor because he or she does not have to be in the fields as long as a conventional farmer.

Tractors consume large quantities of fossil fuels that add to costs while also emitting greenhouse gases (mostly $\mathrm{CO}_{2}$ ) and contributing to global warming when used for ploughing (Grace et al., 2003). Animalbased tillage systems are also expensive since farmers have to maintain and feed a pair of animals for a year for this purpose. Animals also emit methane, a greenhouse gas 21 times more potent for global warming than carbon dioxide (Grace et al., 2003). Zero-tillage reduces these costs and emissions. Farmer surveys in Pakistan and India show that zero-till of wheat after rice reduces cost of production by US\$ 60 per hectare mostly due to less fuel $\left(60-80 \mathrm{~L} \mathrm{ha}^{-1}\right.$ ) and labour (Hobbs \& Gupta, 2004).

Zero tillage minimizes time for establishing a crop. The time required for tillage can also delay timely planting of crops, with subsequent reductions in yield potential (Hobbs \& Gupta 2003). By reducing turnaround time to a minimum, zero-tillage can get crops planted on time, and thus increase yields without greater input cost. Turnaround time in this rice-wheat system from rice to wheat varies from 2 to 45 days, since 2-12 passes of a plough are used by farmers to get a good seedbed. With zero-till wheat this time is reduced to just 1 day (Hobbs \& Gupta 2003).

Zero-tillage combined with permanent soil cover, has been shown to result in a build-up of organic carbon in the surface layers (Campbell et al., 1996a; Lal, 2005). No-tillage minimizes soil organic matter losses and is a promising strategy to maintain or even increase soil $\mathrm{C}$ and $\mathrm{N}$ stocks (Bayer et al., 2000).

The second key principle in CA is to create a permanent organic soil cover which is synonymous to retention of crop residues (mulch). Mulch can allow for growth of organisms within the soil structure. This growth will break down the mulch that is left on the soil surface. The breaking down of this mulch will produce a high organic matter level which will act as a fertilizer for the soil surface. If the practices of CA were being done for many years and enough organic matter was being built up at the surface, then a layer of mulch would start to form. This layer helps prevent soil erosion from taking place and ruining the soils profile or layout.

The layer of mulch will start to become like a buffer zone between soil and mulch that will help reduce wind and water erosion. Rainfall on land that is not protected by a layer of mulch is left open to the elements. But when soils are covered under a layer of mulch, the ground is protected so that the ground is not directly affected by rainfall (Hobbs et al., 2007). This type of ground cover also helps keep the temperature and moisture levels of the soil at a higher level rather than if it was tilled every year (FAO, 2007). Kumar \& Goh (2000) concluded that crop residues of cultivated crops are a significant factor for crop production through their effects on soil physical, chemical and biological functions as well as water and soil quality.

Mulch reduces surface soil crusting, increases water infiltration, reduces run-off and gives higher yield than tilled soils (Cassel et al., 1995; Thierfelder et al., 2005). Similarly, the surface residue, anchored or loose, protects the soil from wind erosion (Michels et al.,1995). Surface mulch helps to reduce water losses from the soil by evaporation and also helps moderate soil temperature. This promotes biological activity and enhances nitrogen mineralization, especially in the surface layers (Dao, 1993; Hatfield \& Pruegar, 1996). This is a very important factor in tropical and subtropical environments.

A cover crop and the resulting mulch or previous crop residue help in reducing weed infestation through competition and not allowing weed seeds the light often needed for germination. There is also evidence of allelopathic properties of cereal residues in respect to inhibiting surface weed seed germination (Steinsiek et al., 1982; Lodhi \& Malik, 1987; Jung et al., 2004). Weeds will be controlled when the cover crop is cut, rolled flat or killed. Farming practice that maintains soil micro-organisms and microbial activity can also lead to weed suppression by the biological agents (Kennedy, 1999). Cover crops contribute to the accumulation of organic matter in the surface soil horizon (Roldan et al., 2003; Alvear et al., 2005; Diekow et al., 2005; Madari et al., 2005; Riley et al., 2005). 
The third principle is the practice of crop rotation with more than two species. Crop rotation can be used best as a disease control against other preferred crops (Hobbs et al., 2007). This process will not allow pests such as insects and weeds to be set into a rotation with specific crops. Rotational crops will act as a natural insecticide and herbicide against specific crops. Not allowing insects or weeds to establish a pattern will help to eliminate problems with yield reduction and infestations within fields (FAO, 2007). Crop rotation can also help in building up a soils infrastructure. Establishing crops in a rotation allows for an extensive build up of rooting zones which will allow for better water infiltration (Hobbs et al., 2007).

Howard (1996) reviewed the cultural control of plant diseases from an historical view and included examples of disease control through rotation. The rotation of different crops with different rooting patterns combined with minimal soil disturbance in zero-till systems promotes a more extensive network of root channels and macro-pores in the soil. This helps in water infiltration to deeper depths. Because rotations increase microbial diversity, the risk of pests and disease outbreaks from pathogenic organisms is reduced, since the biological diversity helps keep pathogenic organisms in check (Leake, 2003).

\section{Pros and Cons of Conservation Agriculture}

Many of the benefits of CA have been mentioned in the above section. In this section an attempt has been made to highlight benefits with problems in a summarized way.

On the side of the conservationist, CA can be seen as beneficial because there is an effort to conserve what people use every day. Since agriculture is one of the most destructive forces against biodiversity, CA can change the way through which humans produce food and energy. These benefits include less erosion possibilities, better water conservation, improvement in air quality due to less emission being produced, and a chance for larger biodiversity in a given area.

On the side of the producer and/or farmer, CA can eventually do all that is done in conventional agriculture, and it can conserve better than conventional agriculture. Theodor Friedrich, specialist in CA, believes "Farmers like it because it gives them a means of conserving, improving and making more efficient use of their natural resources" (FAO, 2006). Producers will find that the benefits of CA will come later rather than sooner. Since CA takes time to build up enough organic matter and have soils become their own fertilizer, the process does not start to work over night. But if producers make it through the first few years of production, results will start to become more satisfactory.

CA is shown to have even higher yields and higher outputs than conventional agriculture once CA has been establish over long periods. Also, a producer has the benefit of knowing that the soil in which his crops are grown is a renewable resource. According to New Standard Encyclopedia (1992), soils are a renewable resource, which means that whatever is taken out of the soil can be put back over time. As long as good soil upkeep is done, the soil will continue to renew itself. This could be very beneficial to a producer who is practicing CA and is looking to keep soils at a productive level for an extended time.

The farmer and/or producer can use this same land in another way when crops have been harvested. The introduction of grazing livestock to a field that once held crops can be beneficial for the producer and also the field itself. Livestock can be used as a natural fertilizer for a producer's field which will then be beneficial for the producer the next year when crops are planted once again. The practice of grazing livestock in a CA helps the farmer who raises crops on that field and the farmer who raises the livestock that graze off that field. Livestock produces compost or manures which are a great help in producing soil fertility (Pawley, 1963). With the practices of CA and grazing livestock on a field for many years can allow for better yields in the following years as long a practices are continued to be followed.

The FAO believes that there are three major benefits from CA.

1. Within fields that are controlled by CA the producer will see an increase in organic matter.

2. The second benefit is an increase in water conservation due layer of organic matter and ground cover to help eliminate transportation and access runoff.

3. The third benefit is an improvement of soil structure and rooting zone. 
Lal (2005) suggested that by adopting CA practices on agricultural land, food security would not only be enhanced but also offset fossil fuel emissions at the rate of $0.5 \mathrm{Pg} \mathrm{C} \mathrm{yr}^{-1}$. Climate change is likely to strongly affect rice-wheat, rice-rice and maize-based cropping systems that, today, account for more than $80 \%$ of the total cereals grown on more than 100 million ha of agricultural lands in South Asia. Global warming may be beneficial in some regions, but harmful in those regions where optimal temperatures already exist. Agronomic and crop management practices have to aim at reducing $\mathrm{CO}_{2}$ and other greenhouse gas emissions by reducing tillage and residue burning and improving nitrogen use efficiency. In the Indo Ganetic Plains (IGP), resource-conserving technologies continue to expand in the rice-wheat cropping systems and save 50-60 L of diesel ha ${ }^{-1}$ plus labour, and significantly reduce release of $\mathrm{CO}_{2}$ to the environment. Methane emissions that have a warming potential 21 times that of $\mathrm{CO}_{2}$ are common and significant in puddle anaerobic paddy fields and also when residues are burnt. This green house gas emission can be mitigated by shifting to an aerobic, direct seeded or no till rice system (Grace et al., 2003). Nitrous oxide has 310 times the warming potential of $\mathrm{CO}_{2}$, and its emissions are affected by poor nitrogen management (Lal, 2005). Sensor-based technologies for measuring normalized differential vegetative index and moisture index have been used in Mexico and South Asia to help improve the efficiency of applied nitrogen and reduce nitrous oxide emissions.

As much as conservation agriculture can benefit the world, there are some problems that come with CA. There are many reasons why conservation agriculture cannot always be a win-win situation.

There are not enough people who can financially turn from a conventional farmer to a conservationist. Within the process of CA comes time; when a producer first starts to process as a conservationist the results can be a financial loss to that certain producer. Since CA is based upon establishing an organic layer and producing its own fertilizer, then this may take time to produce that layer. It can be many years before a producer will start to see better yields than he/she has had previously before. Another financial undertaking is purchasing of new equipment. When starting CA a producer may have to buy new planters or drills in order to produce effectively, also comes the responsibility of harvesting a crop. These financial tasks are ones that may impact whether or not a producer would want to conserve or not.

With the struggle to adapt comes the struggle to make CA grow across the globe. CA has not spread as quickly as most conservationists would like. The reasons for this are because there is not enough pressure for producers in places. But in the tropics there is more of a pressure to change to conservation areas because of the limited resources that are available. Places like Europe have also started to catch onto the ideas and principles of CA, but still nothing much is being done to change due to their being a minimal amount of pressure for people to change their ways of living (FAO, 2006).

With CA comes the idea of producing enough food. With cutting back in fertilizer, not tilling of ground and among other processes comes the responsibility to feed the world. According to the Population Reference Bureau, at the 2000 census count of the world population there were around 6.08 billion people on earth. By 2050 there will be an estimated 9.1 billion people. With this increase comes the responsibility for producers to increase food supply with the same or even less amounts of land to do it on. With CA problems arise in the fact that if farms do not produce as much as conventional ways, then this leaves the world with less food for more people.

Another major problem in CA is the requirement of suitable equipments. Zero-till and CA are bound to fail if suitable equipment is not available to drill seed into residues at the proper depth for good germination. The main requirements of equipment in a CA system are a way to handle loose straw (cutting or moving aside), seed and fertilizer placement, furrow closing and seed/soil compaction, direct drill seeding equipment etc. However the equipments needed in CA are- (a) inverted T coulter, (b) no-till drill using inverted T, (c) disc-type planter, (d) star-wheel punch planter, (e) 'happy planter' where straw picked up and blown behind seeder and (f) disc planter with trash mover (Hobbs et al., 2007).

\section{Conservation agriculture and climatic change}

CA can help mitigate atmospheric greenhouse gas (GHG), both by reducing existing emission sources and by sequestering net carbon. Overall there is insufficient information on the GHG impacts of CA practices, especially for developing countries in the tropics and sub-tropics (Govaerts et al., 2009). Although many studies have examined GHG stocks and fluxes associated with CA systems and various 
CA practices, these data span a wide range of geographies, climates, and agro-ecological zones, and are generally not comparable or amenable to meta-analysis (Nair et al., 2009). Dendooven et al. (2011) evaluated the effect of tillage practice and crop residue management on the net global warming potential (GWP) taking into account soil $\mathrm{C}$ sequestration, emissions of greenhouse gasses from soil, i.e. $\mathrm{CO}_{2}, \mathrm{CH}_{4}$ and $\mathrm{N}_{2} \mathrm{O}$, and fuel used for farm operations (tillage, planting and fertilizer application, harvest) and the production of fertilizer and seeds. Tillage and residue management had little effect on greenhouse gasses emitted from the soil. Maximum difference between the agricultural systems was $242 \mathrm{~kg}$ equivalent $C \mathrm{ha}^{-1}$ $\mathrm{y}^{-1}$. However, the soil organic $\mathrm{C}$ content in the $0-60 \mathrm{~cm}$ layer was affected strongly by tillage and crop residue management. The soil organic $\mathrm{C}$ content was $118 \times 10^{3} \mathrm{~kg} \mathrm{C}^{-1}$ in ZT with residue retention, approximately $40,000 \mathrm{~kg} \mathrm{C} \mathrm{ha}^{-1}$ higher than in practices involving tillage or ZT with residue removal. Taking into account the almost 20-year duration of the experiment, approximately $2000 \mathrm{~kg} \mathrm{C}^{-1} \mathrm{ya}^{-1}$ was sequestered in the soil in $\mathrm{ZT}$ with residue retention compared to tillage or ZT with residue removal (Dendooven et al, 2011). ZT reduced the $C$ emission of farm operations with $74 \mathrm{~kg} \mathrm{C}^{-1} \mathrm{ha}^{-1}$ compared to $\mathrm{CT}$. This may seem a small difference, but while the amount of $\mathrm{C}$ that can be sequestered in soil is finite, the reduction in net $\mathrm{CO}_{2}$ flux to the atmosphere by reduced fossil-fuel use can continue indefinitely (West and Marland, 2002). The net GWP (taking into account soil C sequestration, emissions of GHG from soil and fuel used for farm operations and the production of fertilizer and seeds) was near neutral for ZT with crop residue retention (40 kg CO $\mathrm{Cha}^{-1} \mathrm{y}^{-1}$ ), whereas in the other management practices it was approximately $2000 \mathrm{~kg} \mathrm{CO}_{2}$ ha $^{-1} \mathrm{y}^{-1}$.

$\mathrm{N}$ fertilizers are a significant direct source of emissions of $\mathrm{N}_{2} \mathrm{O}$ and $\mathrm{NO}_{x}$ in the field and an indirect source through fossil fuel energy consumption associated with manufacturing and transport of fertilizers (OrtizMonasterio et al, 2010). Adequate fertilizer management can play an important role in reducing $\mathrm{N}_{2} \mathrm{O}$ and $\mathrm{NO}_{x}$ emissions in the field and increasing the fertilizer efficiency, thereby reducing the necessary fertilizer and associated manufacturing emissions. Sensor-based $N$ management in wheat and maize is a new technology that uses an optical sensor, which measures the normalized difference vegetative index of the canopy. The use of this vegetative index in conjunction with an $\mathrm{N}$ rich strip (a well fertilized part of the field) and a crop algorithm can be used to establish the optimum $\mathrm{N}$ fertilization rate (Raun et al, 2009). This technology optimizes $\mathrm{N}$ rates and minimizes the risk of excess fertilizer application. In addition, the $\mathrm{N}$ fertilizer is applied at the time of high demand by the crop, which in turn reduces the probabilities of generating favorable conditions for $\mathrm{N}_{2} \mathrm{O}$ emissions. Conservation agriculture may adjust $\mathrm{C}$ and $\mathrm{N}$ cycling compared to conventional systems (Govaerts et al, 2006) and thus research is needed to determine whether dose, method and timing of application should be adjusted depending on management system.

The use of agricultural inputs such as irrigation carries a hidden carbon cost (West and Marland, 2002). As mentioned above, the degradation of physical soil quality in conventionally tilled bed (CTB) may have an effect on the efficiency of the use of resources, such as irrigation water. The decreased infiltration in CTB might result in lower irrigation efficiency. Additionally, a better water conservation due to reduced evaporation in permanent bed systems with residue retained may decrease the irrigation requirements compared to CTB. However, more research is needed to determine irrigation water requirements in CA systems compared to conventional systems.

Global warming may be beneficial in some regions, but harmful in those regions where optimal temperatures already exist; an example would be the rice-wheat mega-environments in the IGP that account for $15 \%$ of global wheat production. Agronomic and crop management practices have to aim at reducing $\mathrm{CO}_{2}$ and other greenhouse gas emissions by reducing tillage and residue burning and improving nitrogen use efficiency. In the IGP, resource-conserving technologies continue to expand in the ricewheat cropping systems and save 50-60 liter of diesel ha ${ }^{-1}$ plus labour, and significantly reduce release of $\mathrm{CO}_{2}$ to the environment. $\mathrm{CH}_{4}$ emissions that have a warming potential 21 times that of $\mathrm{CO}_{2}$ are common and significant in puddled anaerobic paddy fields and also when residues are burnt. This GHG emission can be mitigated by shifting to an aerobic, direct seeded or no till (NT) rice system. A review of the other benefits of direct seeding and NT in South Asia can be found in (Grace et al. 2003). $\mathrm{N}_{2} \mathrm{O}$ has 310 times the warming potential of $\mathrm{C}_{2} \mathrm{O}$, and its emissions are affected by poor nitrogen management. Sensor-based technologies for measuring normalized differential vegetative index and moisture index have been used in Mexico and South Asia to help improve the efficiency of applied $\mathrm{N}$ and reduce $\mathrm{N}_{2} \mathrm{O}$ emissions (Lal, 2005). 


\section{Future Development of Conservation Agriculture}

As in any other businesses, producers and conservationist are always looking towards the future. In this case CA is a very important process to be looked at for future generations to have a chance to produce. There are many organizations that have been created to help educate and inform producers and conservationist in the world of CA. These organizations can help to inform, conduct research and buy land in order to preserve animals and plants (New Standard Encyclopedia, 1992).

Another way in which CA is looking to the future is through prevention. According to the European Journal of Agronomy producers are looking for ways to reduce leaching problems within their fields. These producers are using the same principles within CA, in that they are leaving cover over their fields in order to save fields from erosion and leaching of chemicals out of fields (Kirchmann \& Thorvaldsson, 2000). Processes and studies like this are allowing for a better understanding on how to conserve on what we are using and finding ways to put back something that may have been lost before.

Circulation of plant nutrients can be a vital part to conserving for the future. An example of this would be the use of animal manure. This process has been done for quite some time now, but the future is looking towards how to handle and conserve the nutrients within manure for a longer time. But besides just animal waste also food and urbanized waste are being looked towards as a way to use growth within CA (Kirchmann \& Thorvaldsson, 2000). Turning these products from waste to being used to grow crops and improve yields is something that would be beneficial for conservationists and producers.

\section{Conclusion}

Crop production in the next decade will have to produce more food from less land by making more efficient use of natural resources and with minimal impact on the environment. Only by doing this will food production keep pace with demand and the productivity of land be preserved for future generations. This will be a tall order for agricultural scientists, extension personnel and farmers. Use of productive but more sustainable management practices described in this paper can help resolve this problem. Crop and soil management systems that help improve soil health parameters (physical, biological and chemical) and reduce farmer costs are essential. Development of appropriate equipment to allow these systems to be successfully adopted by farmers is a prerequisite for success. Overcoming traditional mindsets about tillage by promoting farmer experimentation with this technology in a participatory way will help accelerate adoption. Encouraging donors to support this long-term applied research with sustainable funding is also an urgent requirement.

\section{References}

Alvear, M., Rosas, A., Rouanet, J.L. and Borie, F. 2005. Effects of three soil tillage systems on some biological activities in an Ultisol from southern Chile. Soil Tillage Res. 82: 195-202.

Bayer, C., Mielniczuk, J., Amado, T.J.C., Martin-Neto, L. and Fernandes, S.V. 2000. Organic matter storage in a sandy loam Acrisol affected by tillage and cropping systems in southern Brazil. Soil Tillage Res. 54: 101-109.

Berger, A., Friedrich, T. and Kienzle, J. 2010. Soils, Plant Growth and Crop Production - Conservation Agriculture. 1: 108-112.

Campbell, C.A., McConkey, B.G., Zentner, R.P., Selles, F. and Curtin, D. 1996. Long-term effects of tillage and crop rotations on soil organic $C$ and $N$ in a clay soil in southwestern Saskatchewan. Can. J. Soil Sci. 76, 395-401.

Cassel, D.K., Raczkowski, C.W. and Denton, H.P. 1995. Tillage effects on corn production and soil physical conditions. Soil Sci. Soc. Am. J. 59, 1436-1443.

Dao, T.H. 1993. Tillage and winter wheat residue management effects on water infiltration and storage. Soil Sci. Soc. Am. J. 57, 1586-1595.

Dendooven, L., Patino-Zuniga, L., Verhulst N., Luna-Guido M., Marsch, R. and Govaerts, B. 2011. Global warming potential of agricultural systems with contrasting tillage and residue management in the central highlands of Mexico. J. Farming Systems Res. Extension. 4: 35-66.

Diekow, J., Mielniczuk, J., Knicker, H., Bayer, C., Dick, D. P. and Kogel-Knabner, I. 2005. Soil C and N stocks as affected by cropping systems and nitrogen fertilization in a southern Brazil Acrisol managed under no-tillage for 17 years. Soil Tillage Res. 81, 87-95.

Dumanski, J., Peiretti, R., Benetis, J., McGarry, D. and Pieri, C. 2006. The paradigm of conservation tillage. Proc. World Assoc. Soil and Water Conserv., P1: 58-64.

FAO (Food and Agriculture Organization). 2006. Agriculture and Consumer Protection Department. Rome, Italy. (Accessed November 2007). 
FAO (Food and Agriculture Organization). 2007. Agriculture and Consumer Protection Department. Rome, Italy. (Accessed November 2007).

Govaerts, B., Sayre, K. D., Ceballos-Ramirez, J. M., Luna-Guido, M. L., Limon-Ortega, A., Deckers, J. and Dendooven, L. 2006. Conventionally tilled and permanent raised beds with different crop residue management: Effects on soil $\mathrm{C}$ and $\mathrm{N}$ dynamics', Plant and Soil, 280: 143-155.

Govaerts, B., Sayre, K. D., Goudeseune, B., De Corte, P., Lichter, K., Dendooven, L. and Deckers, J. 2009. Conservation agriculture as a sustainable option for the central Mexican highlands, Soil \& Tillage Research, 103: 222-230.

Grace, P.R., Harrington, L., Jain, M.C. and Robertson, G.P. 2003. Long-term sustainability of the tropical and subtropical rice wheat system: an environmental perspective. 65: 27-43.

Green, B., Sayre, K.D. and Deckers, J. 2005. Stable high yields and zero tillage and permanent bed planting. Field Crops Res. 94: 33-42.

Gupta, R., Hobbs, P.R. and Sayre, K.D. 2007. The role of conservation agriculture in sustainable agriculture. The Royal Society. Pg. 1-13.

Hatfield, K.L. and Pruegar, J.H. 1996. Microclimate effects of crop residues on biological processes. Theor. Appl. Climatol. 54: 47-59.

Hobbs, P.R. and Gupta, R.K. 2003. Resource conserving technologies for wheat in rice-wheat systems. In Improving the productivity and sustainability of rice-wheat systems: issues and impact. 65: 149-171.

Hobbs, P.R. and Gupta, R.K. 2004. Problems and challenges of no-till farming for the rice-wheat systems of the Indo-Gangetic Plains in South Asia. New York: NY: Ohio State University; Marcel Dekker, paper 6, pp. 101-119.

Hobbs, P.R., Sayre, K.D. and Gupta, R. 2007. The role of conservation agriculture in sustainable agriculture. Philosophical transactions of the Royal Society of London. Series B, Biol. Sciences 363(1491): 543-555.

Howard, R.J. 1996. Cultural control of plant diseases: a historical perpective. Can. J. Plant Pathol. 18, 145-150.

Jung, W.S., Kim, K.H., Ahn, J.K., Hahn, S.J. and Chung, I.M. 2004. Allelopathic potential of rice (Oryza sativa L.) residues against Echinochloa crusgalli. Crop Protect. 23, 211-218.

Kennedy, A.C. 1999. Soil microorganisms for weed management. J. Crop Prod. 2, 123-138.

Kirchmann, H., and Thorvaldsson, G. 2000. European Journal of Agronomy. Challenging Targets for Future Agriculture. Vol. 12, Issues 3-4. Pg 145-161.

Kumar, K. and Goh, K.M. 2000. Crop residues and management practices: effects on soil quality, soil nitrogen dynamics, crop yield and nitrogen recovery. Adv. Agron. 68, 198-279.

Lal, R. 2005. Enhancing crop yields in the developing countries through restoration of the soil organic carbon pool in agricultural lands. Land Degrad. Dev 17, 197-209.

Leake, A.R. 2003. Integrated pest management for conservation agriculture. In Conservation agriculture: environment, farmers experiences, innovations, socio-economy, policy. pp. 271-279.

Lodhi, M.A.K. and Malik, K.A. 1987. Allelopathy in agroecosystems: wheat phytotoxicity and its possible role in crop rotation. J. Chem. Ecol. 13, 1881-1891.

Madari, B., Machado, P.L.O.A., Torres, E., de Andrade, A.G. and Valencia, L.I.O. 2005. No tillage and crop rotation effects on soil aggregation and organic carbon in a Rhodic Ferralsol from southern Brazil. Soil Tillage Res. 80, 185-200.

Michels, K., Sivakumar, M.V.K. and Allison, B.E. 1995. Wind erosion control using crop residue. I. Effects on soil flux and soil properties. Field Crops Res. 40, 101-110.

Nair, P.K.R.,. Kumar, B.M, and Nair, V.D. 2009. Agroforestry as a strategy for carbon sequestration. Journal of Plant Nutrition and Soil Science 172: 10-23.

New Standard Encyclopedia. 1992. Standard Educational Operation. Chicago, Illinois. Pg(s) A-141, C-546.

Ortiz-Monasterio, I., Wassmann, R., Govaerts, B., Hosen, Y., Katayanagi, N. and Verhulst, N. 2010. Greenhouse gas mitigation in the main cereal systems: rice, wheat and maize. Climate Change and Crop Production, CABI, Oxford shire. pp 151-176

Pawley, W.H. 1963. Possibilities of Increasing World Food Production. Food and Agriculture Organization of the United Nations. Rome, Italy. P. 98.

Population Reference Bureau. 2007. Washington, D.C. (Accessed December 2007).

Raun, W.R., Ortiz-Monasterio, I. and Solie, J.B. 2009. Temporally and spatially dependent nitrogen management in diverse environments .pp 203-214.

Riley, H.C.F., Bleken, M.A., Abrahamsen, S., Bergjord, A.K. and Bakken, A.K. 2005. Effects of alternative tillage systems on soil quality and yield of spring cereals on silty clay loam and sandy loam soils in cool, wet climate of central Norway. Soil Tillage Res. 80, 79-93.

Roldan, A., Caravaca, F., Hernandez, M.T., Garcia, C. Sanchez-Brito, C., Velasquez, M. and Tiscareno, M. 2003. No-tillage, crop residue additions, legume cover cropping effects on soil quality characteristics under maize in Patzcuaro watershed (Mexico). Soil Tillage Res. 72, 65-73.

Steinsiek, J.W., Oliver, L.R. and Collins, F. 1982. Allelopathic potential of wheat (Triticum aestivum) straw on selected weed species. Weed Sci. 30, 495-497.

Thierfelder, C., Amezquita, E. and Stahr, K. 2005. Effects of intensifying organic manuring and tillage practices on penetration resistance and infiltration rate. Soil Tillage Res. 82, 211-226.

West, T. O. and Marland, G. 2002. A synthesis of carbon sequestration, carbon emissions, and net carbon flux in agriculture: Comparing tillage practices in the United States', Agriculture, Ecosystems and Environment. 91: 217-232. 